\title{
Emotional Intelligence and Gender as Correlates of Burnout Syndrome among Nurses in the University of Port Harcourt Teaching Hospital Rivers State
}

\author{
Ekechukwu Rosemary Obiagaeri ${ }^{1^{*}}$, Obicheina Georgy ${ }^{2}$ \\ ${ }^{I}$ Department of Educational Psychology, Faculty of Education, University of Port Harcourt, Rivers State, \\ Nigeria \\ ${ }^{2}$ Department of Human Kinetics and Health Education, Faculty of Education, University of Port Harcourt, \\ Rivers State, Nigeria
}

*Corresponding Author: Ekechukwu Rosemary Obiagaeri, Department of Educational Psychology, Faculty of Education, University of Port Harcourt, Rivers State, Nigeria

\begin{abstract}
The study investigated emotional intelligence and gender as correlates of burnout syndrome among nurses in the University of Port Harcourt Teaching Hospital Rivers State. The study used the correlational research design. The population of the study comprised of all 750 nurses in the University of Port Harcourt Teaching Hospital. A sample of 300 nurses from Paediatrics Ward, Male Ward, Female Ward and Intensive Care Unit (ICU), were randomly selected using the simple random sampling technique (balloting). Two instruments titled; Maslach Burnout Scale (MBS) by Maslach (1996) and Emotional Intelligence Inventory (EII) by Akinboye (2005) were used to collect data for the study. The Cronbach Alpha reliability was used to establish the internal consistency reliability coefficients of 0.87 and 0.69 respectively. Responses to the research questions were analyzed with mean and standard deviation, while the hypotheses will be tested with multiple regression associated with independent sample t-test statistics. The findings of the study revealed that emotional intelligence (self-awareness, self-management, self-motivation, social awareness, and relationship management) jointly and independently relate significantly to burnout syndrome among nurses in University of Port Harcourt Teaching Hospital in Rivers State. The result also showed that gender relates significantly to burnout syndrome among nurses in University of Port Harcourt Teaching Hospital. Based on the findings of the study it was recommended among others that the Management of the University of Port Harcourt Teaching Hospital should look into the unconducive work environment of nurses and make necessary changes as this may affect not only the nurses but also other workers and patients within the hospital who are not included in this study.
\end{abstract}

Keywords: Emotional Intelligence (self-awareness, self-management, self-motivation, social awareness, and relationship management) and Burnout Syndrome.

\section{INTRODUCTION}

The term 'burnout' was coined in the 1970s to describe the physical and emotional exhaustion that workers may experience on the job, especially those who provide some type of service to others (Irving, Dobkin \& Park, 2009). Burnout is a term that has been used to describe observable symptoms an employee presents in responding to the perceived demands and expectations of a stressful, nonrewarding work place (Ekechukwu, 2009). Robinson, Ode and Hilmert (2011) described burnout as a situation in which workers are continuously subjected to stressors that they find themselves unable to cope with, which in turn makes them feel exhausted, lacking in energy, and mentally fatigued. It is an extreme case of chronic, prolonged stress which is likely to emerge when work is unchallenging, unrewarding and lacking in positive feedback and recognition (Schaufeli \& Enzmann 1998). Burnout is a state of emotional, physical, and mental exhaustion caused by excessive and prolonged stress which occurs when one feels overwhelmed, emotionally drained and unable to meet constant demands (Schaufeli \& Bakker, 2004), as the stress continues, the individual begins to lose the interest and motivation that led him/her to take on a certain role in the first place, eventually the person feels like he/she has nothing more to give (Glory, 2011). 
Maslach and Jackson as cited in Guillermo Elena, Lucia, Emilia, Cristina and Jose (2018), described burnout as comprising three dimensions; (1) emotional exhaustion, characterized by lack of energy and enthusiasm and depletion of emotional resources; (2) depersonalization, described as negative attitudes toward clients, colleagues, and the organization; and (3) reduced personal accomplishment, which is manifested as a worker's tendency towards negative self-evaluation, showing dissatisfaction with their own performance at work. Burnout has also been associated with high employment turnover, excessive absenteeism, negative job attitudes, low morale and a reduction in willingness to help others (Abushaikha \& Saca-Hazboun, 2009). Burnout is a specific kind of occupational stress among human service professionals, as a result of the demanding and emotionally charged relationships between caregivers and their recipients (Maslach, 2011).

Symptoms of burnout syndrome are nonspecific but include tiredness, headaches, eating problems, insomnia, irritability, emotional instability and rigidity in relationships with other people (Kilikova \&Sramka, 2006). Other symptoms include negative job attitudes, negative self-concept, outburst of anger, loss of concentration, increased error rate, suicidal thoughts and suicide, substance use and abuse (Rakovan \& Kacmarova, 2014). Some behavioural impact of burnout syndrome include reduced level of job performance, errors of judgment, diminished interest in social activities, feelings of detachment from others, reduced personal accomplishment, depersonalization, emotional exhaustion, irresponsibility, low morale, absenteeism and early retirement (Jaramillo, 2005). Burnout reduces productivity and saps an individual's energy, leaving the person feeling increasingly helpless, hopeless, cynical, and resentful (Maslach as cited in Syed, 2013).

Burnout has often been mistaken for stress. Burisch (2006) explained that although the symptoms of stress may be quite similar to those of burnout, there are distinctions between both. He further explained even though workers experience stress because of long work schedules, shift work or general workload, they may not experience burnout however, stress can intensify the level of burnout in an individual. Maslach (2001) maintained that the stress symptoms are more physical resulting in pressure and hyperactivity whereas burnout is emotional resulting in helplessness and frustration.

There are debates that among health care professionals, nurses are prone to burnout syndrome due to the stressful nature of their work (Abushaikha, \& Saca-Hazboun, 2009). Nurses are expected to deliver humane, empathetic, culturally sensitive, proficient and moral care, inworking environments with limited resources, reduced staff strength and increasing responsibilities. Nurses work tirelessly rendering care to critically and chronically ill patients who are between life and death in an environment where there is black of tolerance for error (Rowe, 2003). They are sometimes required to work over-time, even 24-hours a day with little or no time to rest or even have a meal. This continuous exposure to stressors can exert intense psychological and physical pressures on nurses leading to burnout syndrome. The role of nurses has long been regarded as stress-filled based upon the physical labor, human suffering, work hours, staffing, and interpersonal relationships that are central to what the work nurses do (Lukpata, Lukpata, Ndiok \& Mgbekem, 2013). Arafa (2003) stressed that the stressful nature of the nursing profession results in job dissatisfaction and burnout syndrome among nurses. It has also been observed that the nature of the nursing profession requires nurses to be constantly on alert whether on or off duty, attending to sick patients and this has significant effects on nurses' health, emotions, interpersonal relationships and level of resilience. Burnout due to exposure to stressful work environments among nurses also results in negative physiological and psychological consequences like headache, muscular tensions, fatigue, depression, and hypertension. It therefore imperative that this study examines emotional intelligence and gender as correlates of burnout syndrome among nurses in University of Port Harcourt Teaching Hospital in Rivers State.

Emotional intelligence is the capability of individuals to recognize their own emotions and those of others, establish relations with other individuals, discern between different feelings and label them appropriately, use emotional information to guide thinking and behaviour, and manage or adjust emotions to adapt to surrounding environment and achieve one's goal (Coleman, 2008). It is generally said that emotional intelligence made up of five components, they are; self-awareness, selfmanagement, self-motivation, and social-awareness and relationship management (Goleman, 1995). Self-awareness is the first component of emotional intelligence which indicates knowing ones feeling and emotions or recognizing a feeling as it happens. It is the ability to monitor feeling from moment to moment. Goleman (1995) observed that handling feeling, in an appropriate ways help to build self- 
awareness and that people who are low in this ability are prone to feeling of distress and may shy away from performing a task assigned to them or avoid certain situation whereas, those who are high are more resilient to life's setbacks and upsets, and are more confident in challenging situations. The second component is self-management. This is otherwise known as managing one's emotion. It is the ability to regulate distressing affects like anxiety and anger and to inhibit emotional impulsivity.

Self-motivation is the third emotional intelligence component, which is marshaling emotion in pursuit of a goal, people who have this ability tend to be more productive and effective in whatever they undertake. Social awareness, the fourth emotional intelligence component, encompasses the competency of empathy, and is the fundamental of people skill which makes them well suited for the caring professions such as nurses and social workers like teachers (Arvey, Renz, and Watson, 1998). Finally, the fifth component of emotional intelligence is relationship management as a social skill that poses the ability to manage emotions, in others. Several studies have suggested that these components of emotional intelligence may relate to burnout syndrome (Laschinger, Shamian, \& Thomson, 2001; Gam1 an, Corrigan, \& Morris, 2002). Grezt cited in Akpan (2011) revealed that individuals with low emotional intelligence do not possess the ability to create social relationships that help their day to day activity. Budnik (2003) stressed that emotional intelligence has a significant relationship with burnout among nurses.

Gender is another variable that may be considered in relation to burnout syndrome among nurses. Gender is the range of physical, biological, mental and behavioural characteristics pertaining to and differentiating between masculinity and feminity (Haig, 2004). Depending on the context, the term may refer to biological sex (i.e. the state of being male, female), sex based social structure (including gender roles and other social roles) or gender identity (Udry, 2004). According to the Oxford Advanced Learner's Dictionary, gender is a state of being male or female with reference to social or cultural differences (Oxford English Mini dictionary, 2003). Weckwerth and Flynn (2006) stressed that female nurses suffer more from burnout than men. They further explained that women are feeble by nature and tend to be more susceptible to stress and burnout. Kalimo and Hakanen as cited in Adekola (2012) discovered that male and female differ significantly in the ways they cope with stress. According to them, women usually take sick leave more often than men and were clearly more active in seeking outside help for their problems, while men thought more and more of retiring as their burnout gets worse. Notwithstanding, some studies have detected no difference in their level of burnout among male and female nurses (Adekola, 2012). Purvanova and Muros (2010) stressed that gender is not a predictive factor for burnout among nurses. Based on these, the study is geared toward examining emotional intelligence and gender as correlates of burnout syndrome among nurses in University of Port Harcourt Teaching Hospital in Rivers State.

\section{AIM AND OBJECTIVES OF THE STUDY}

The study examined emotional intelligence and gender as correlates of burnout syndrome among nurses in University of Port Harcourt Teaching Hospital in Rivers State. Specifically, the study sought to;

- Determine the extent to which emotional intelligence dimensions (self-awareness, selfmanagement, self-motivation, social awareness, and relationship management) jointly relate to burnout syndrome among nurses in University of Port Harcourt Teaching Hospital.

- Determine the extent to which emotional intelligence dimensions (self-awareness, selfmanagement, self-motivation, social awareness, and relationship management) independently relate to burnout syndrome among nurses in University of Port Harcourt Teaching Hospital

- Determine the extent to which gender relate to burnout syndrome among nurses in University of Port Harcourt Teaching Hospital.

\subsection{Research Questions}

The following research questions guided the study;

- To which extent does emotional intelligence dimensions (self-awareness, self-management, selfmotivation, social awareness, and relationship management) jointly relate to burnout syndrome among nurses in University of Port Harcourt Teaching Hospital? 
- To which extent does emotional intelligence dimensions (self-awareness, self-management, selfmotivation, social awareness, and relationship management) independently relate to burnout syndrome among nurses in University of Port Harcourt Teaching Hospital?

- To what extent does gender relate to burnout syndrome among nurses in University of Port Harcourt Teaching Hospital?

\subsection{Hypotheses}

The following hypotheses which were tested at 0.05 level of significance guided the study;

- Emotional intelligence dimensions (self-awareness, self-management, self-motivation, social awareness, and relationship management) do not jointly relate to burnout syndrome among nurses in University of Port Harcourt Teaching Hospital

- Emotional intelligence dimensions (self-awareness, self-management, self-motivation, social awareness, and relationship management) do not independently relate to burnout syndrome among nurses in University of Port Harcourt Teaching Hospital

- Gender does not significantly relate to burnout syndrome among nurses in University of Port Harcourt Teaching Hospital

\section{Methodology}

The study used the correlational research design. The population of the study comprised of all 750 nurses in the University of Port Harcourt Teaching Hospital. A sample of 300 nurses from Paediatrics Ward, Male Ward, Female Ward and Intensive Care Unit (ICU), were randomly selected using the simple random sampling technique (balloting). Two instruments titled; Maslach Burnout Scale (MBS) by Maslach (1996) and Emotional intelligence inventory (EI) by Akinboye (2005) were used to collect data for the study. The instruments were designed on a four point Likert scale of Strongly Agree $(\mathrm{SA})=4$, Agree $(\mathrm{A})=3$, Disagree $(\mathrm{D})=2$, and Strongly Disagree $(\mathrm{SD})=1$. The Cronbach Alpha reliability was used to establish the internal consistency reliability coefficients of 0.87 and 0.69 respectively. Responses to the research questions were analyzed with mean and standard deviation, while the hypotheses will be tested with multiple regression associated with independent sample t-test statistics.

\section{RESUltS AND DisCuSSION}

Research Question 1: To which extent does emotional intelligence dimensions (self-awareness, selfmanagement, self-motivation, social awareness, and relationship management) jointly relate to burnout syndrome among nurses in University of Port Harcourt Teaching Hospital?

Hypothesis 1: Emotional intelligence dimensions (self-awareness, self-management, self-motivation, social awareness, and relationship management) do not jointly relate to burnout syndrome among nurses in University of Port Harcourt Teaching Hospital

Table1: Summary of T-test Analysis on the joint relationship of emotional intelligence on burnout syndrome among nurses

\begin{tabular}{|l|l|l|l|l|l|l|l|l|}
\hline Variables & $\mathbf{N}$ & $\bar{X}$ & SD & Level of sig & Df & T-cal & Critical Value & Decision \\
\hline Emotional Intelligence & 300 & 3.34 & 0.81 & 0.05 & 298 & 4.11 & 1.96 & $\begin{array}{l}\text { Significant(Reject } \\
\left.\text { Ho }_{1}\right)\end{array}$ \\
\hline Burnout Syndrome & 300 & 2.89 & 0.94 & & & & & \\
\hline
\end{tabular}

From the result of the table, the calculated t-test value stood at 4.11, while t-critical value stood at 1.96 using 298 degree of freedom at 0.05 level of significance. At 0.05 level of significance and 298 degrees of freedom, the calculated t-value of 4.11 is greater than the t-critical value of 1.96. Hence there is a significant relationship between the variables. Consequently, the researcher rejected the null hypothesis, and concluded that emotional intelligence (self-awareness, self-management, selfmotivation, social awareness, and relationship management) jointly relates significantly to burnout syndrome among nurses in University of Port Harcourt Teaching Hospital.

Research Question 2: To which extent does emotional intelligence dimensions (self-awareness, selfmanagement, self-motivation, social awareness, and relationship management) independently relate to burnout syndrome among nurses in University of Port Harcourt Teaching Hospital? 
Emotional Intelligence and Gender as Correlates of Burnout Syndrome among Nurses in the University of Port Harcourt Teaching Hospital Rivers State

Hypothesis 2: Emotional intelligence dimensions (self-awareness, self-management, self-motivation, social awareness, and relationship management) do not independently relate to burnout syndrome among nurses in University of Port Harcourt Teaching Hospital

Table2: Regression Analysis, on the extent emotional intelligence independently relate to burnout syndrome among nurses in University of Port Harcourt Teaching Hospital

\begin{tabular}{|l|l|c|c|c|c|}
\hline S/No & \multicolumn{1}{|c|}{ Variable } & R & R Square & Adjusted R Square & Sig. F Change \\
\hline 1 & Self- Awareness & 0.634 & 0.402 & 0.611 & 0.000 \\
\hline 2 & Self-Management & 0.906 & 0.821 & 0.772 & 0.004 \\
\hline 3 & Self-Motivation & 0.677 & 0.458 & 0.455 & 0.044 \\
\hline 4 & Social-Awareness & 0.881 & 0.776 & 0.698 & 0.031 \\
\hline 5 & Relationship Management & 0.995 & 0.990 & 0.886 & 0.001 \\
\hline
\end{tabular}

From table 2 above, the correlation coefficient $(r=0.634)$ between self-awareness and burnout syndrome is positive and strong. It reveals that $40 \%$ of burnout syndrome can be explained by selfawareness. The correlation coefficient $(\mathrm{r}=0.906)$ between self-management and burnout syndrome is positive and strong. This reveals that, $82 \%$ of change experienced in burnout syndrome can be explained by self-management. The correlation coefficient $(\mathrm{r}=0.677)$ between self-motivation and burnout syndrome is positive and strong. This reveals that $46 \%$ of burnout syndrome can be explained by self-motivation. The correlation coefficient $(\mathrm{r}=0.881)$ between social-awareness and burnout syndrome is positive and strong. This reveals that $78 \%$ of burnout syndrome can be explained by social-awareness. Furthermore, the correlation coefficient $(r=0.995)$ between relationship management and burnout syndrome is positive and strong. This reveals that $99 \%$ of burnout syndrome can be explained by relationship management.

Research Question 3: To what extent does gender relate to burnout syndrome among nurses in University of Port Harcourt Teaching Hospital?

Hypothesis 3: Gender does not significantly relate to burnout syndrome among nurses in University of Port Harcourt Teaching Hospital

Table3: showing the extent gender relates to burnout syndrome among nurses in University of Port Harcourt Teaching Hospital

\begin{tabular}{|l|l|l|l|l|l|l|l|}
\hline \multicolumn{1}{|c|}{ Gender } & \multicolumn{1}{|c|}{$\mathbf{N}$} & \multicolumn{1}{c|}{$\bar{X}$} & \multicolumn{1}{c|}{ Std.Dev. } & \multicolumn{1}{c|}{ Crti-t } & \multicolumn{1}{c|}{ Cal-t } & \multicolumn{1}{c|}{ Df } & \multicolumn{1}{|c|}{ P } \\
\hline Male & 89 & 39.59 & 9.71 & 1.96 & 2.255 & 298 & S \\
\hline Female & 211 & 42.54 & 10.59 & & & & \\
\hline
\end{tabular}

The result of data analyzed showed that male nurses had $\bar{X}=39.59, \mathrm{SD}=9.71$, Female nurses $\bar{X}$ $=42.54, \mathrm{SD}=10.59$, with a cal. t. of $2.255, \mathrm{df}=298$, crit. t. $=1.96$. Since cal. $\mathrm{t}$ is higher than the crit. t. it means that the hypothesis of no significant relationship is rejected. Therefore, there is/exist a significant relationship between gender and burnout syndrome. Further analysis revealed that female nurses tend to have burnout more compared to male nurses.

\section{SumMary OF FindingS}

The results obtained after data analysis are summarized below;

- Emotional intelligence dimensions (self-awareness, self-management, self-motivation, social awareness, and relationship management) jointly and independently relates significantly to burnout syndrome among nurses in University of Port Harcourt Teaching Hospital in Rivers State.

- Gender significantly relates significantly to burnout syndrome among nurses in University of Port Harcourt Teaching Hospital in Rivers State.

\section{DISCUSSION OF FINDINGS}

\subsection{Emotional Intelligence and Burnout Syndrome}

The finding of the present study revealed that emotional intelligence (self-awareness, selfmanagement, self-motivation, social awareness, and relationship management) jointly and independently relate significantly to burnout syndrome among nurses in University of Port Harcourt Teaching Hospital in Rivers State. Therefore, the null hypothesis was rejected. This implies that 
emotional intelligence (self-awareness, self-management, self-motivation, social awareness, and relationship management) significantly relates to burnout syndrome. The finding of this study agrees with an earlier study by Priscilla (2004) who found out that low emotional intelligence significantly relates to burnout syndrome among nurses. Grezt cited in Akpan (2011) also found out that individuals with low emotional intelligence are susceptible to experiencing burnout.

\subsection{Gender and Burnout Syndrome}

The result of the study showed that significantly relates significantly to burnout syndrome among nurses in University of Port Harcourt Teaching Hospital in Rivers State. Further analysis of the result revealed that female nurses tend to have burnout more compared to male nurses. The null hypothesis of no significant relationship with between gender and burnout syndrome was rejected. The finding of the present study is in agreement with an earlier study by Weckwerth and Flynn (2006) who found out that gender significantly relates to burnout syndrome among nurses, and that female nurses suffer more from burnout than male nurses. They further explained that women are feeble by nature and tend to be more susceptible to stress and burnout. Kalimo and Hakanen (1998) also found out that gender significantly relates to burnout syndrome and that male and female differ significantly in the ways they cope with burnout.

\section{CONCLUSION}

Burnout has been conceptualized as a state in which a person is continuously subjected to stressors that he finds himself unable to cope with, which in turn makes he feel emotionally exhausted, lacking in energy, and mentally fatigued. The role of nurses in the health profession makes them more susceptible to developing burnout syndrome. Nurses work tirelessly rendering care to critically and chronically ill patients who are between life and death in an environment where there is black of tolerance for error. They are sometimes required to work over-time, even 24-hours a day with little or no time to rest or even have a meal. They are constantly on alert whether on or off duty, attending to sick patients and this significant affects their health, emotions, interpersonal relationships and level of resilience. Burnout among nurses also results in negative physiological and psychological consequences like headache, muscular tensions, fatigue, depression, and hypertension. This study has showed that emotional intelligence (self-awareness, self-management, self-motivation, social awareness, and relationship management) jointly and independently relate significantly to burnout syndrome among nurses in University of Port Harcourt Teaching Hospital in Rivers State. The result also showed that gender relates significantly to burnout syndrome among nurses in University of Port Harcourt Teaching Hospital.

\section{RECOMMENDATIONS}

Based on the findings of this study, the researcher recommended the following;

- Nurses should be encouraged to share their work experiences with their colleagues and seek the help of professional counsellors. Also regular medical checkup should be carried out to monitor nurses pulse rates and other vital bodily clues for the possible symptoms of burnout.

- The Management of the University of Port Harcourt Teaching Hospital should look into the unconducive work environment of nurses and make necessary changes as this may affect not only the nurses but also other workers and patients within the hospital who are not included in this study.

- Counselling rehabilitation and recreational centers should be set up in various parts of the country where counselling services should be obtained.

\section{REFERENCES}

[1] Abushaikha, L. \& Saca-Hazboun, H. (2009). Job satisfaction and burnout among Palestinian nurses. Eastern Mediterranean Health Journal, 15, 190-197.

[2] Adekola B (2012). Work burnout experience among university non teaching staff: A gender approach. Int. J. Aca. Res. Bus. Soc. Sci., (1): 128-135.

[3] Arafa, M.A. (2003). Predictors of psychological well-being of nurses in Alexandria, Egypt. International Journal of Nursing Practice, 9, 313-320.

[4] Arvey, R. W., Renz, G. L., \& Watson, T. W. (1998). Emotionality and job performance: Implications for personnel selection. In G. R. Ferris (Ed.), Research in personnel and human resources management, 16, 103-147. 
Emotional Intelligence and Gender as Correlates of Burnout Syndrome among Nurses in the University of Port Harcourt Teaching Hospital Rivers State

[5] Budnik, M. F. (2003). Emotional intelligence and Bburnout: Influence on the intent of staff nurses to leave nursing. PhD dissertation, University of Phoenix, Published by ProQuest LLC

[6] Burisch M (2006) In search of a theory: some rumination on the nature and etiology of burnout. In Professional Burn-out: Recent Developments in Theory and Research, (Eds) W B Schaufeli, C Maslach, T Marek, London: Taylor and Francis. pp. 75-93.

[7] Ekechukwu, R. O. (2009). Correlates of burnout among policemen in Rivers State. A Ph.D. Thesis submitted to the Department of Educational Psychology, Guidance and Counselling, University of Port Harcourt.

[8] Goleman, D. (1995). Emotional intelligence: Why it can matter more than IQ. New York: Bantam Books.

[9] Guillermo, C. D., Elena, O., Lucia, R. B., \& Emilia, D. F. (2018). Gender, marital status and children as risk factors for burnout in nurses: A meta-analytic study. International Journal of Environmental Research and Public Health, 15(10), 1-13.

[10] Irving, J.A., Dobkin, P.L. \& Park, J. (2009). Cultivating mindfulness in healthcare professionals: A review of empirical studies of Mindfulness-Based Stress Reduction (MBSR). Complementary Therapies in Clinical Practice, 15, 61-66.

[11] Kilikova, M., \& Sramka, M. (2006). Causes and consequences of the burnout syndrome in healthcare. Nursing Horizon, 3(3), 94-96

[12] Laschinger, H., Shamian, J., \& Thomson, D. (2001). A hospital level analysis of the work environment and workforce health indicators for registered nurses in Ontario acute care hospitals. Canadian Journal of Nursing Research, 33(4), 35-50

[13] Lukpata, F.E., Lukpata, O.H., Ndiok, A. \& Mgbekem, M.A. (2013). Nurses workplace stress and patient safety in General Hospital Calabar, Cross River State, Nigeria. International Professional Nursing Journal, 11, 87-92.

[14] Maslach, C. (2011). Engagement research: Some thoughts from a burnout perspective. European Journal of Work and Organizational Psychology, 20 (1), 47-52

[15] Maslach, C., Schaufeli, W.B., \& Leiter, M.P. (2001). Job burnout. In ST Fiske, DL Schacter, C ZahnWaxler Eds. Ann. Rev. Psychol., 52: 397-422.

[16] Oxford University Press (2003). Oxford English Minidictionary, 6th ed.

[17] Priscilla, H. David, P. P., \& Alberto, C. (2004). Burnout syndrome in hospital nurses. Paper presented at BHAA International, Chicago, IL.

[18] Purvanova, R.K., \& Muros, J.P (2010). Gender differences in burnout: A meta-analysis. J. Voc. Beh., 77(2): 168- 185.

[19] Rakova, J., \& Kacmarova, L. (2014). Analysis of selected indicators in the context of health and social care for seniors. In Szyska M et al. (eds.) International and non-institutional forms of support for older people 239-251

[20] Robinson, M.D., Ode, S. \& Hilmert, C. (2011). Regulated and unregulated forms of cortisol reactivity: A dual vulnerability model. Psychosomatic Medicine, 73, 250-256.

[21] Rowe, J. (2003). The suffering of the healer. Nursing Forum, 38, 16-20.

[22] Schaufeli WB, Enzmann D (1998). The burnout companion to study and research: A critical analysis. London. Taylor \& Francis Handleiding(Utrecht Burnout Scale-UBOS: Testmanual).Lisse, Neth.: Swets \& Zeitlinger

[23] Schaufeli, W. B., \& Bakker, A. B. (2004). Job demands, job resources and their relationship with bournout and engagement. A multi-sample study. Journal of Organizational Behaviour, 25, 293-437.

[24] Syed, G.A., \& Alain, R. (2013). Impact of overload and coping strategies on stress and burnout of university teachers. Retrieved from RePEc:hal:jounl:hal-00958210

[25] Weckwerth, A.C., \& Flyn, D.M. (2006). Effect of sex on perceived support and burnout in university students. Col. Stud. J., 40(2): 237-249.

Citation: Ekechukwu Rosemary Obiagaeri, Obicheina Georgy. "Emotional Intelligence and Gender as Correlates of Burnout Syndrome among Nurses in the University of Port Harcourt Teaching Hospital Rivers State ". International Journal of Humanities Social Sciences and Education (IJHSSE), vol. 7, no.1, 2020, pp. 81-87. doi: http://dx.doi.org/10.20431/2349-0381.0701009.

Copyright: (C) 2020 Authors. This is an open-access article distributed under the terms of the Creative Commons Attribution License, which permits unrestricted use, distribution, and reproduction in any medium, provided the original author and source are credited. 